\title{
UM ENFOQUE AO DESPERDÍCIO
}

\section{Carlos Lourenço A. Trombini ${ }^{1}$}

\section{Máris de Cassia Ribeiro Vendrame ${ }^{2}$}

RESUMO: Na atual fase em que a economia passa por constantes mudanças e forte concorrência no mercado mundial é preponderante que as empresas defrontem-se com grande resistência no segmento de mercado onde atuam. Para se destacarem umas das outras, é fundamental uma adequada administração da produção sobre os índices de desperdício, objetivando maior produtividade e redução de custos. Assim, as empresas que são bem administradas e fazem com que seus colaboradores tenham enfoque na execução dos produtos com qualidade e com o intuito de atender as necessidades dos clientes, terão um diferencial para alavancar a produtividade e a qualidade e, consequentemente tornarem-se competitivas no mercado. Fundada há mais de onze anos, a empresa estudada, atua no segmento de abate e comercialização de frango resfriado e seus derivados. A empresa preocupa-se em manter a qualidade do produto com segurança, minimizando prazos de entregas e custos, promovendo a satisfação dos clientes, pois este é um fator primordial para o processo e resultados empresariais. Atualmente uma das maiores preocupações da empresa, tem sido, através da utilização de

\footnotetext{
${ }^{1}$ Bacharel em Administração, especialista em Marketig e Recursos Humanos, Mestrando em Meio Ambiente e Desenvolvimento Regional pela Unoeste, Professor e Coordenador do Curso de Administração do Centro Paula Souza de Educação Tecnológica, carlos.trombini@bol.com.br;

${ }^{2}$ Bacharel em Administração, Mestre em Administração pela UNIMEP, Professora e Coordenadora do Curso de Administração do UNISALESIANO, maris@unisalesiano.br
} 
ferramentas e técnicas administrativas, garantir a maximização dos índices de produtividade, redução do desperdício de alimentos.

Palavras-chave: Desperdício. Produtividade. Frango.

\section{INTRODUÇÃO}

Diante de um mercado competitivo como o atual, é necessário, para a perpetuidade das organizações, que elas se destaquem umas das outras.

Uma das maneiras mais eficazes para se garantir a perenidade é a redução de custos e, consequentemente, o aumento da produtividade. Partindo desse pressuposto, nasce a finalidade desta pesquisa científica que teml objetivo de demonstrar como o fator desperdício é prejudicial à produtividade de uma empresa, e também como os fatores que conduzem ao desperdício podem ser combatidos.

"Desperdício é tudo aquilo que não agrega valor ao produto" CABANAS (2003). A partir dessa definição, pode-se verificar formas de desperdício em uma mesma empresa: desperdício de tempo, de recursos materiais e patrimoniais, de capital, de oportunidades, etc. No caso, este estudo científico abordará o fator desperdício na linha de produção, onde é visualizado de maneira mais clara.

A maior dificuldade quando se fala em desperdício dentro de uma empresa não está em saber onde ele ocorre, mas sim, como deve ser combatido.

Diante disso surgiu a questão: Através da aplicação de técnicas de combate ao desperdício no processo produtivo é possível alavancar a produtividade da empresa $X$ ? Surge então a seguinte hipótese que norteia o trabalho: o controle eficiente do processo produtivo é determinante para a redução do desperdício.

A pesquisa de campo sobre o desperdício na linha de produção, na referida empresa $X$.

No caso da empresa estudada, o desperdício de alimentos se traduz em prejuízo a mesma e em fator desmotivacional, uma vez que os colaboradores por vezes sofrem com a falta de alimentos em suas casas. É valido ressaltar ainda que o mundo sofre com o 
problema da fome e este poderia ser combatido se as empresas alimentícias fossem mais eficazes no combate ao desperdício.

Para desenvolver essa pesquisa, foi utilizado o método de observação sistemática e revisão bibliográfica.

\section{DESENVOLVIMENTO}

As atuais circunstâncias da economia globais vêm provocando constantes reflexões da sociedade coorporativa mundial, dentre tais pensamentos um dos que mais provocam preocupação esta relacionada à redução de custos, tendo como objetivo o aumento da competitividade de uma empresa em relação a seus concorrentes e a perpetuidade em um mercado onde as margens de lucro são cada vez menores.

A partir deste contexto a redução dos índices de desperdício deve ser meta constante em qualquer organização mercalógica, para tanto as empresas devem ser bem administradas e fazer com que seus colaboradores tenham enfoque na exigência dos produtos buscando satisfazer as necessidades e desejos dos clientes sempre aos menores custos possíveis, torna-se então compreensível que o combate ao desperdício é uma das maneiras mais adequadas de se reduzir custos.

\section{DESPERDICIO}

O ato de desperdiçar, alternativa ou cumulativamente, vem da falta de competência na utilização dos recursos disponíveis, sejam eles humanos, materiais ou financeiros, transformando este ato em gastos ou despesas inúteis.

Segundo Rocha (1995), o substantivo desperdício se traduz como "tudo aquilo que não acrescenta valor no produto ou quaisquer atividades improdutivas". Desta forma o conceito de desperdício está associado à ausência de valor agregado.

TIPOS DE DESPERDÍCIO 
Corrêa e Gianesi (1996), classificam os tipos de desperdícios baseados no sistema just in time, classificação esta utilizada por Shigeo Shingo, uma reconhecida autoridade em JIT, consultor de prestígio internacional, além de ter sido durante vários anos engenheiro da Toyota Motor Company, no Japão. Shingo identifica sete categorias de desperdícios: desperdício de superprodução, de espera, de transporte, de processamento, de movimento, de produção de produtos defeituosos e de estoques. Este trabalho cientifico dará enfoque ao desperdício de processamento, considerado o mais comum na empresa $\mathrm{X}$, sendo aquele que afetava a empresa de maneira mais negativa quanto à produtividade.

\section{VANTAGENS E MEIOS DO COMBATE AO DESPERDÍCIO}

Vantagens de combate ao desperdício

As principais vantagens que uma empresa obtém com a utilização de técnicas de combate ao desperdício são: um processo produtivo mais eficiente e eficaz, colaboradores mais envolvidos com a empresa, maior valor agregado e mais qualidade dos produtos e aproveitamento de materiais antes jogados fora.

Toda empresa competitiva está sempre buscando maior eficiência e eficácia em seu processo produtivo, o combate aos índices de desperdício através de técnicas de administração da produção torna mais tangíveis as metas de redução de tais índices.

É valido lembrar que somente a correta administração da produção não basta, o investimento no capital humano é importante, e visa à busca da participação ativa dos colaboradores na distribuição de responsabilidades, no caso da empresa $X$ este é o fator essencial à redução de desperdício, já que os empregados são mais sensíveis e perceptivos quanto ao desperdício que ocorre na linha de produção.

Técnicas de combate ao desperdício

As mudanças ocorridas devido a atual globalização da economia vêm afetando o processo de tomada de decisão dos negócios nas organizações, seja qual for o mercado de atuação, por um lado existem clientes cada vez mais qualidade dos produtos e serviços 
prestados, com uma gama de diversos produtos, as empresas cada vez mais tem se preocupado em manter os níveis de estoque exatamente nas medidas necessárias.

Tais forças exercem forte pressão no processo de tomada de decisão de produção. Através da utilização da informática, principalmente a partir da década de 80 , os sistemas de controle de estoque, possível dimensionar as reais necessidades de estoque conforme a demanda da produção e consequentemente evitar desperdícios.

Os sistemas de planejamento de materiais preocupam-se basicamente com a mensuração dos níveis de estoque. Redução de custos ou maximização dos lucros, provenientes de uma perfeita adequação dos estoques ao tamanho das necessidades. (CABAÑAS, 2003).

Algumas técnicas, apoiadas pela constante evolução da informática têm proporcionado bons resultados quanto à diminuição dos níveis de desperdício e dos custos produtivos, proporcionando uma produção de forma inteligente nas empresas.

Planejamento e controle de produção - PCP

Segundo Rocha (1995), o PCP é um órgão auxiliar que dita as normas às linhas de fabricação, visando um fluxo ordenado e continuo do processo produtivo.

Isso decorre da utilização eficiente dos meios de produção, como a gestão adequada de estoque, possibilitando o planejamento adequado à demanda da produção para determinada pelo pedido do cliente.

Controle da produção

Atividade de decidir sobre o melhor emprego dos recursos de produção, assegurando a execução do que foi previsto de modo que atenda as flutuações de demanda.

Just-in-time/Kanban

A técnica just-in-time nasceu no Japão, fruto da incansável luta japonesa na busca da racionalização de trabalho, seu objetivo está centrado na eliminação do 
desperdício, entendendo-se como desperdício tudo aquilo que não acrescenta valor ao produto ou quaisquer atividades improdutivas.(ROCHA, 1995, p. 200).

A essência da criação do just-in-time está na melhoria continua do processo produtivo através da redução de estoques e diminuição de custos, exigindo um abastecimento ou desabastecimento da produção no tempo certo, no lugar certo e exatamente na quantidade certa, objetivando capacitar a empresa a produzir somente 0 necessário ao atendimento à demanda com qualidade assegurada.

A técnica just-in-time é de difícil aplicação e raramente alcança a efetividade já que pessoas participam do processo sendo que estas nem sempre estão totalmente capacitadas ou comprometidas. Dessa forma pode-se considerar a filosofia utópica, porém é através do estabelecimento de metas não exequíveis que o processo é constantemente aprimorado e os níveis de desperdício chegam próximos a zero.

Vale ressaltar a importância dos fornecedores para o bom funcionamento do just-intime, a confiabilidade nos equipamentos de produção, a política de manutenção adequada, tais fatores são fundamentais para a qualificação do processo e a eficácia da filosofia justin-time.

A grande dificuldade da filosofia just-in-time reside em encontrar o tempo certo para realizar determinada tarefa. Um dos modos de atenuar essa dificuldade é através do uso da técnica Kanban, cartão em japonês, criado e desenvolvido pela Toyota e utilizada na operacionalidade da meta just-in-time, constituindo-se em um sistema eficaz e de baixo investimento.

A técnica Kanban visa controlar o movimento de materiais ou a operação desses materias, controlando o estoque entre as fases do processo.

Segundo Rocha (1995), o sistema Kanban permite controlar os níveis de estoque por meio da visualização dos cartões, já que com a diminuição dos níveis de estoque o cartão se torna visível, informando o momento de reposição do estoque. Percebesse que a ferramenta Kanban apresenta um bom funcionamento e é de importância considerável para a concretização do just-in-time, facilitando o controle de produção, diminuindo o desperdício e os níveis de estoque, por um investimento irrisório.

Just-in-time II 
A filosofia do just-in-time II surge com o objetivo de acrescentar eficiência a primeira versão da técnica, nessa nova versão o fornecedor é trazido para a fabrica da empresa cliente, sendo que o representante do fornecedor permanece em tempo integral na fabrica, essa evolução facilita a comunicação entre os parceiros diminuindo o led time e em conseqüência facilitando o controle e a reposição dos matériais necessários, o que reduz o estoque entre as fases do processo e o desperdício, já que diminui a possibilidade de quebra no fluxo de produtos na linha de produção e dos estoques.

O just-in-time II representa um avanço em relação a outros sistemas just-in-time por proporcionara estrutura organizacional necessária para melhorar a coordenação com o fornecedor integrando os processos de logística, produção e compras. (RITZMAN; KRAJEWSKI, 2004, p. 411).

Material Requeriment Planning - MRP

O MRP constitui-se como um dos sistemas de controle de produção mais eficientes, lida principalmente com suprimento de peças e componentes cujas demandas dependem do produto final. Essa ferramenta passou a ser mais utilizada após a década de 60, através do aprimoramento da informática.

O MRP é um sistema que estabelece uma serie de procedimentos e regras de tomada de decisão, objetivando atende as necessidades da produção em uma seqüência de tempo logicamente determinada para cada componente do produto final, sendo possível, se for o caso, replanejar as necessidades de materiais a cada nova programação de produção, registros de inventários ou composição de produtos, o MRP proporciona vantagens como a manutenção de níveis razoáveis de estoques de segurança, minimização de inventários, programação de produção baseada na demanda real e na previsão de vendas do produto final, o que melhora a produtividade da empresa já que diminui os materiais em processamento os custos e a possibilidade de desperdício.

Como planeja as necessidades de cada item, melhora 0 atendimento aos consumidores, minimiza o material em processamento e aumenta a eficiência da fabrica; com isso consegue melhor gestão de estoques, melhores custos 
operacionais e, consequentemente, maiores margens de lucro. (RUSSOMANO, 1995, p. 201).

MRP II ou ERP

Assim como o MRP, o MRP II ou ERP (Enterprise Resourse Planing), é um sistema que se baseia na lógica do calculo de necessidades de materiais, cujo objetivo é o mesmo da primeira versão do sistema, planejar o abastecimento dos itens componentes dos produtos em processamento para que não ocorram excessos o falta de insumos, por exemplo. O diferencial acrescentado pelo MRP II é que ele permite a integração do planejamento operacional com o financeiro.

O funcionamento do MRP II equivale ao de sua primeira versão, porém, as necessidades de materiais são convergidas em unidades monetárias, permitindo que a área financeira e de produção planejem as necessidades de materiais sem quebrar o fluxo financeiro, além do que o conhecimento prévio de grandes saídas de caixa possibilita melhores negociações de empréstimo e linhas de crédito mais acessíveis.

Optimized Production Tecnology - OPT

O OPT é uma técnica de combate ao desperdício a ser utilizada em nível operacional, porém, para sua implantação se faz necessária a pratica de treinamentos em todos os níveis da organização, já que a alta gerencia deve se comprometer com a filosofia básica do OPT.

Basicamente o OPT se mostra a favor de um balanceamento adequado do fluxo de produção e não das capacidades, o que só é possível ao se evidenciar os gargalos do sistema, segundo o OPT, dessa forma todos os recursos não-gargalos do sistema devem ser programados de acordo com os processos que restringem a capacidade produtiva do mesmo sistema. Se essa coordenação não existir fatalmente haveria estoque entre as fases do processo o que aumentaria os riscos de desperdício.

\section{Programa 8S}


O programa 8S vem com o objetivo de complementar a filosofia básica do $5 \mathrm{~S}$, sugere um conjunto de ações que deve tanto ser realizado pela organização quanto pelas pessoas que fazem parte desta organização. Seu objetivo é o da ordenação dos ambientes, da disciplina, economia determinação e união, bem como o da eliminação da percas, treinamento dos colaboradores, motivação, liderança e comunicação, resultando em um ambiente mais agradável e produtivo. È necessário uma constante reavaliação e aprimoramento dos sensos, por meio de feedback, objetivando cada vez mais a eficiência do processo.

Para que o programa tenha sucesso, alem do envolvimento de toda a organização, é necessário também que se tenha conhecimento da importância da avaliação e do controle de todas as etapas dos sensos, de forma que, com o feedback o programa seja continuamente melhorado. (COSTA et al, 2003, p. 32).

\section{DESCRIÇÃO DO PROCESSO PRODUTIVO}

A Empresa $X$ possui um processo produtivo linear, dividido em seis fases, que se apresentam na ordem, abaixo descrita.

Recepção e descarregamento

Nesse setor é possível observar que conforme a demanda e os recursos disponíveis, o tempo de espera para o abate das aves do caminhão que aguarda para descarregar pode variar, mas não ultrapassa a uma hora e trinta minutos. Assim que possível, as caixas das aves são descarregadas por meio de uma rampa que funciona por gravidade, sendo as aves, uma a uma, alocadas em seus ganchos de sustentação aguardando o início da industrialização.

Finaliza-se assim a primeira fase do processo produtivo.

Sangria 
As falhas na sangria não são muitas, porém, quando ocorrem, comprometem o aproveitamento total da matéria-prima.

Desperdício do setor

Pode-se observar através da figura que, quando a sangria não é bem realizada, não se aproveita a ave em sua totalidade, sendo esta destinada à graxaria. Este desperdício, assim como a maioria dos desperdícios encontrados na empresa, a X não perde, mas deixa de ganhar mais.

A maneira de se evitar o desperdício neste setor é provocar um maior comprometimento dos colaboradores responsáveis por ele, pois a sangria é feita de modo manual.

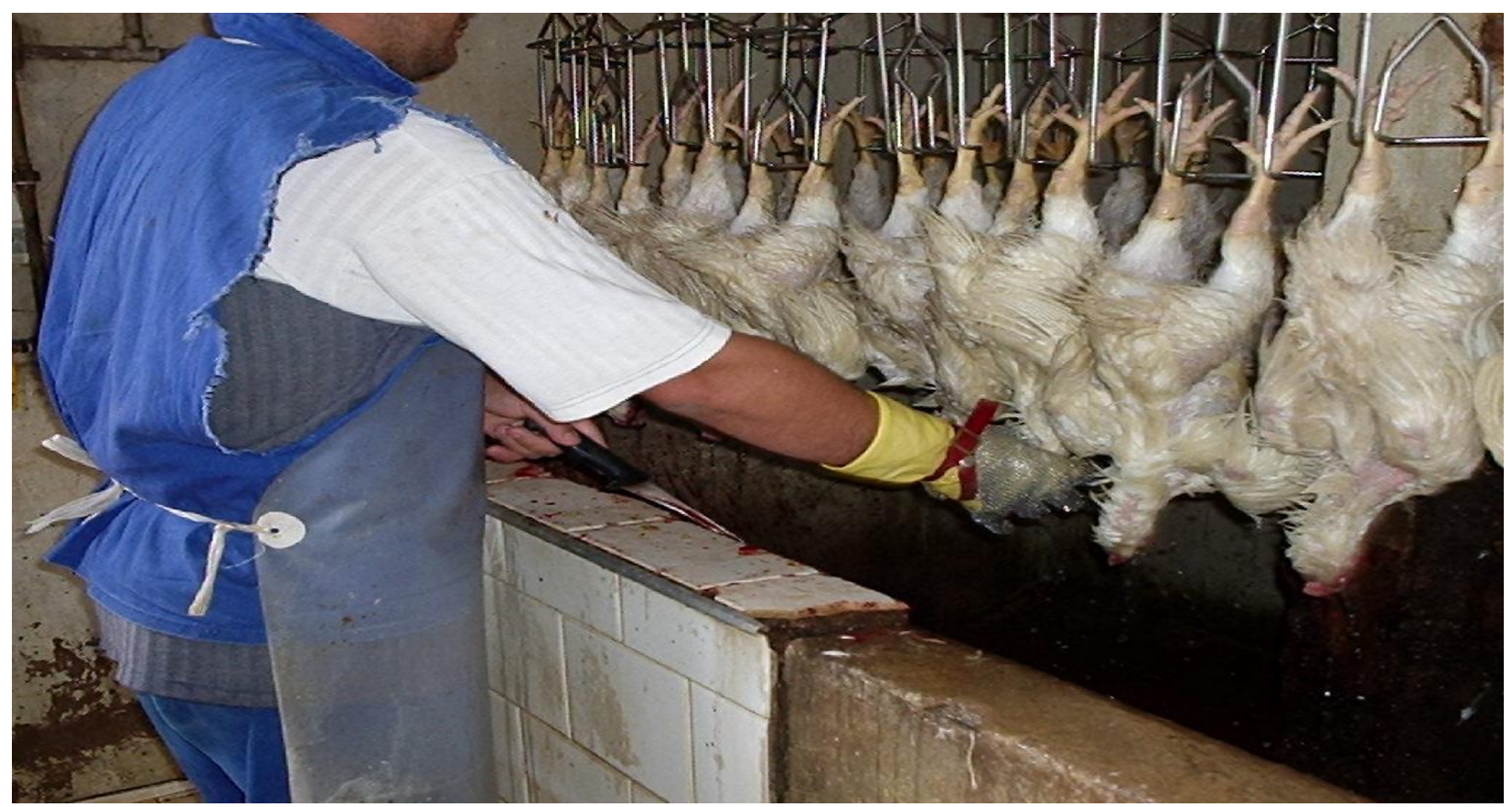

Figura 1: Sangria bem realizada.

Setor de escaldagem 
Desperdício do setor

Através do Método da Observação Sistemática pode-se observar o seguinte:

- conforme indica a foto, os frangos alocados em seus ganchos de sustentação pelos empregados, devido à ação das paletas da máquina, da conseqüente vibração característica, da má engenharia dos ganchos, da desmotivação e conseqüente descomprometimento dos colaboradores, que colocam a matériaprima de maneira inadequada em seus sustentadores, as aves acabam por se soltar e caem ao chão. A alta temperatura a que são expostas faz com que muitas aves acabem se estragando até que sejam retiradas do local, já que a máquina não pode parar até que toda a produção sofra um processo de reabastecimento por um outro carregamento de aves vivas. Normalmente, a industrialização de uma ave exige cerca de uma hora e meia, tempo suficiente para que as que caíram durante a escaldagem tornem-se impróprias ao consumo.

Este problema poderia ser evitado ou, ao menos minimizado, através de uma reengenharia dos ganchos de sustentação, impossibilitando que as aves se soltem, e de uma política de conscientização e motivação dos colaboradores, fazendo com que se empenhem mais no exercício de suas tarefas, por exemplo, uma participação no lucro da empresa e a melhoria salarial.

Processo de evisceração

Desperdício do setor

Através do estudo de caso, verificou-se que:

- os frangos são alocados em ganchos de modo que as vísceras fiquem penduradas no interior da ave sustentadas por alguma víscera que não foi retirada totalmente. É justamente neste ponto que ocorre o desperdício, pois existem dois canais: um que leva os restos das vísceras para que se tornem 
farinha de frango ou irem para a graxaria, e um outro canal que conduzirá o que se aproveita do interior da ave, que são os chamados miúdos (coração, moela e fígado). O desperdício caracteriza-se quando as vísceras e os miúdos a serem comercializados são levados para o canal inadequado, ou seja, quando são conduzidos para a fábrica de farinha ou à graxaria, conforme figura.

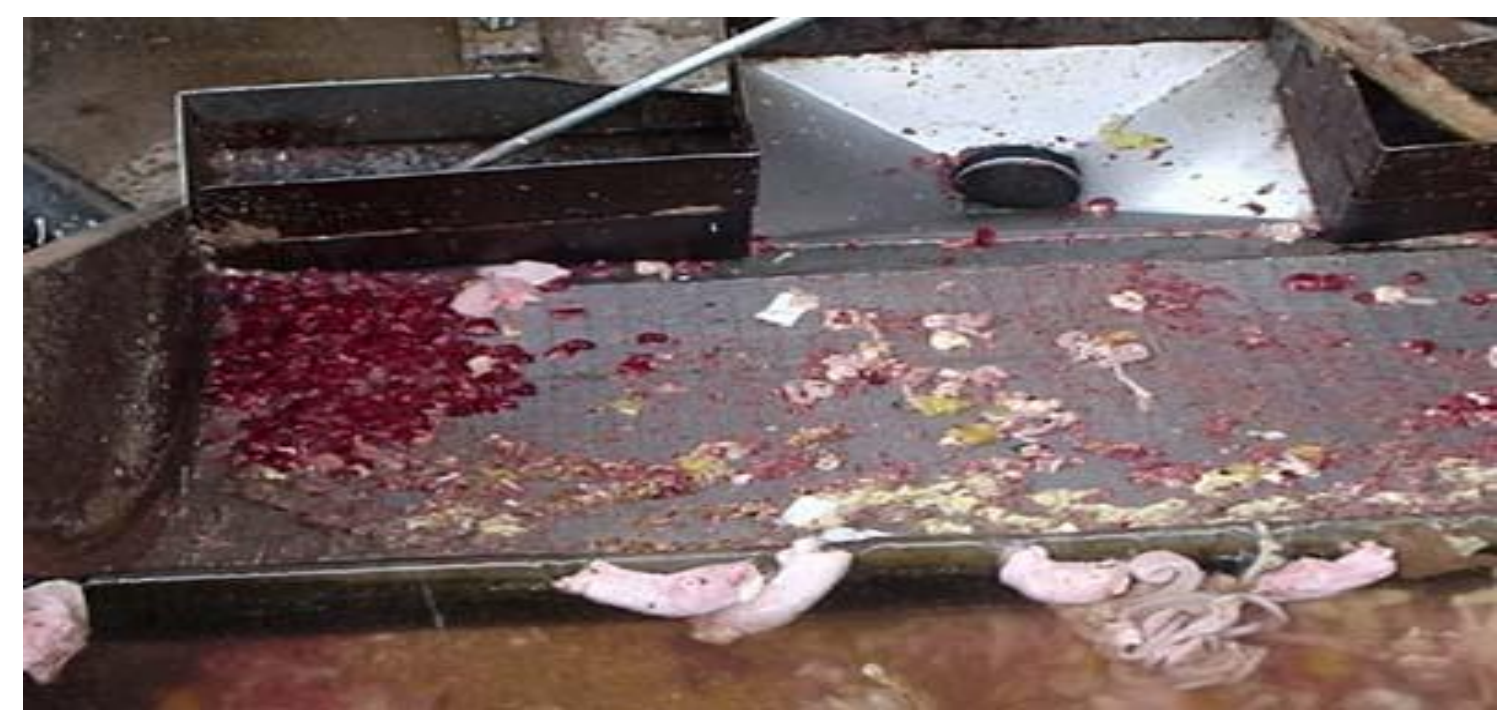

Figura 2: Perdas na evisceração.

Também faz parte deste processo o corte do pescoço e dos pés. No primeiro o desperdício é provocado pelo mau alinhamento da guilhotina, sendo que esta fará com que ao invés de se cortar o pescoço, corte-se também parte da asa em momento inadequado, não podendo mais ser utilizada para comercialização por fugir dos padrões de qualidade. Já no segundo corte, que diz respeito aos pés, o desperdício ocorre quando os mesmos não estão colocados de maneira correta nos ganchos fazendo com que caiam em local inadequado, inviabilizando seu comércio.

Devido ao processo de evisceração, assim como a maior parte do processo produtivo da $X$ ser manual, esse desperdício pode ser sanado pelo treinamento e conscientização das pessoas que realizam o processo, pois o desperdício só ocorre devido as partes envolvidas não serem retiradas de maneira correta. Já no caso do pescoço e dos 
pés, basta que seja feita a manutenção periódica da guilhotina e a verificação correta dos ganchos.

Pré-chiller

Esta fase inicia-se ao final da evisceração onde os frangos passam por compartimento com água, em alta temperatura, que tem como objetivo fazer com que frango atinja uma temperatura de $16^{\circ} \mathrm{C}$, preestabelecida por lei. Este processo tem como objetivo fazer com que os póros dos frangos se abram absorvendo água aumentando assim seu volume, além do que a alta temperatura proporciona a esterilização da ave, deixando-a apropriada para a sequencia do processo.

Chiller

Inicia-se após o pré-chiller, tendo função contrária à fase anterior, ou seja, seu objetivo é diminuir a temperatura do frango fazendo com que este tenha uma variação de $16^{\circ} \mathrm{C}$ para $5^{\circ} \mathrm{C}$, tornando assim a temperatura do mesmo apropriada quanto às especificações legais. Vale lembrar que a queda da temperatura é ocasionada pelo gelo.

Coxa e sobre-coxa

Desperdício do setor

É possível observar através do método da observação sistemática que:

- o mau corte da coxa e sobre-coxa ocasiona grandes perdas, sendo estas visíveis quando se analisam as sobras que restam no dorso conforme será citado. A má execução deste corte retira partes que estariam agregadas a outros produtos como, por exemplo, o filé e o peito do frango. A diferença de peso entre o corte ideal e o corte inadequado é de, em média, 30 gramas por pedaço, conforme mostra a figura abaixo. 

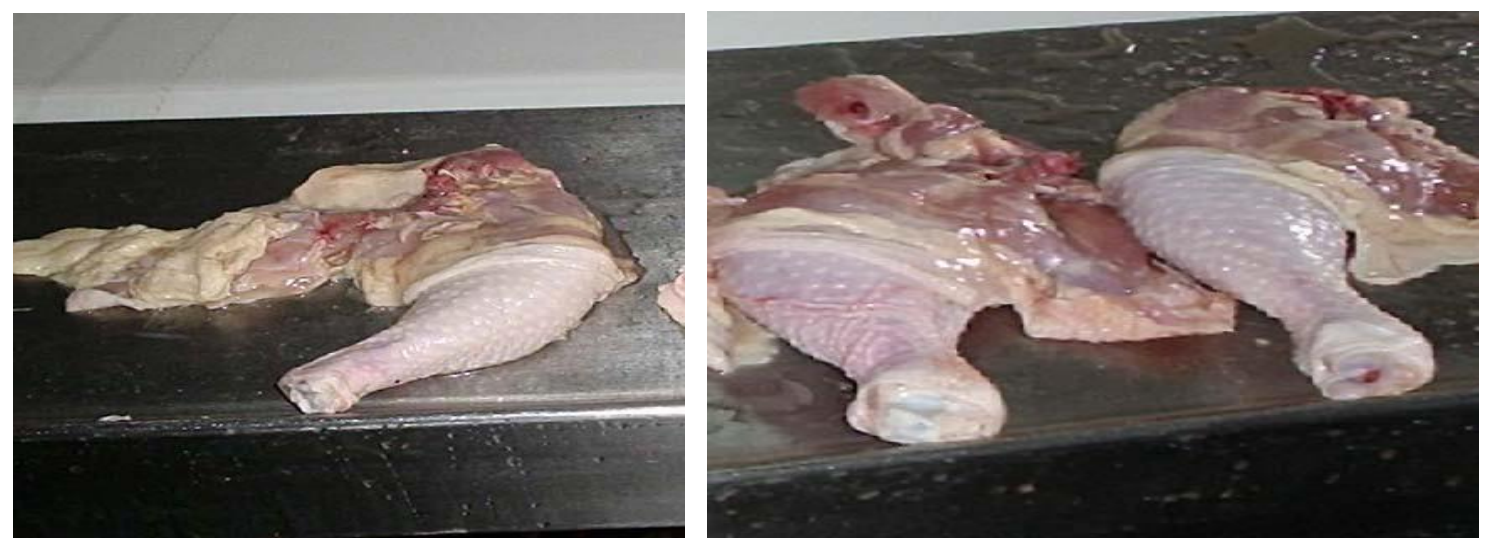

Figura 3: comparação entre o corte mal feito (à esquerda) e o corte bem feito (à direita)

De acordo com depoimento do profissional encarregado, fica claro que este tipo de desperdício poderia ser minimizado com uma melhor preparação dos colaboradores que realizam esta fase do processo e de maior disponibilidade de recursos por parte da empresa.

Corte do filé

Desperdício do setor

Através da observação sistemática pode-se notar que:

- o desperdício ocorrido está diretamente relacionado ao manuseio dos colaboradores na industrialização do produto, bem como na falta de recursos oferecidos pela empresa para a realização da atividade. Nota-se que, após efetuado o corte, existe ainda grande concentração de carne junto ao dorso, carne esta que não é aproveitada para o consumo humano, sendo destinada à produção de graxa. Portanto, a empresa deixa de obter uma margem de lucro maior no que diz respeito a este tipo de corte. 

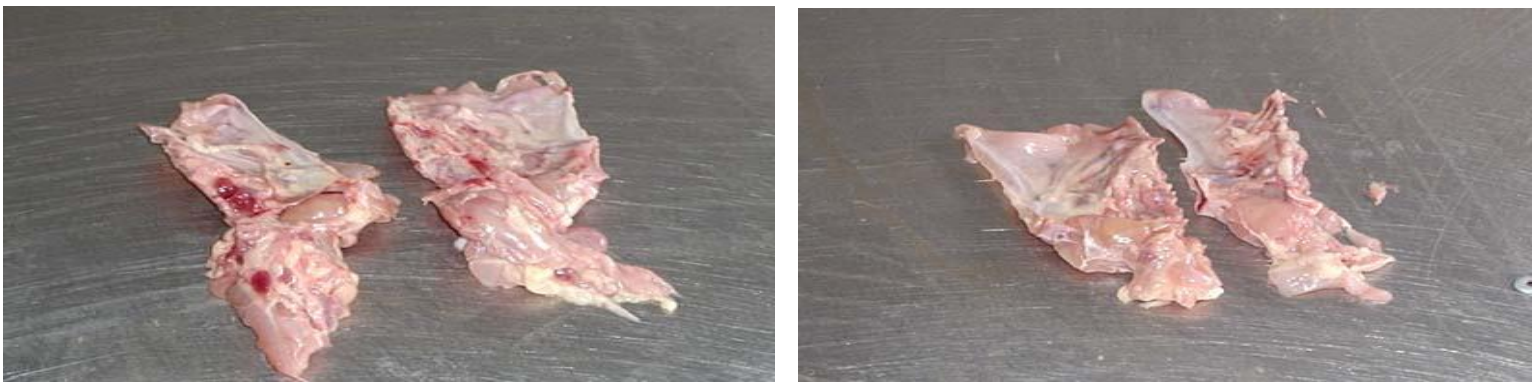

Figura 4: Comparação do corte mal feito (à esquerda) e o corte bem feito (à direita)

Acredita-se que a maneira de evitar esta perda seria através de uma política de conscientização dos colaboradores quanto a necessidade de se diminuir o desperdício bem como uma maior quantidade de recursos tecnológicos, o que possibilitaria a melhor realização do trabalho.

Resíduos no dorso

Desperdício do setor

É possível verificar através do método da observação sistemática que:

- existe um acúmulo de carne na carcaça do frango, cerca de 90 gramas por frango em média, podendo variar conforme o tamanho da ave e a demanda do momento. Por esta carne, que faz parte do peito, das asas, da sobrecoxa das aves, não ser vendida juntamente com essas partes, a carcaça bem como toda a carne que nela fica anexada incorretamente é destinada à produção de graxa e vendida ao preço de $R \$ 0,20$ o quilo, valor irrisório, se comparado aos $R \$ 2,20$ o quilo que poderia ser vendida se fosse realmente destinado ao mercado de carne avícola. Dessa forma, é possível constatar uma das mais graves formas de desperdício existentes no Frigorífico Noroeste, que pode ser considerado como desperdício de matéria-prima ou até mesmo desperdício de oportunidade, uma vez que se deixa de agregar valor, no caso, massa corporal, a um produto que representa uma margem de lucratividade maior, a carne em pedaços, e 
incorretamente utiliza-se carne própria ao consumo humano em um produto menos lucrativo.
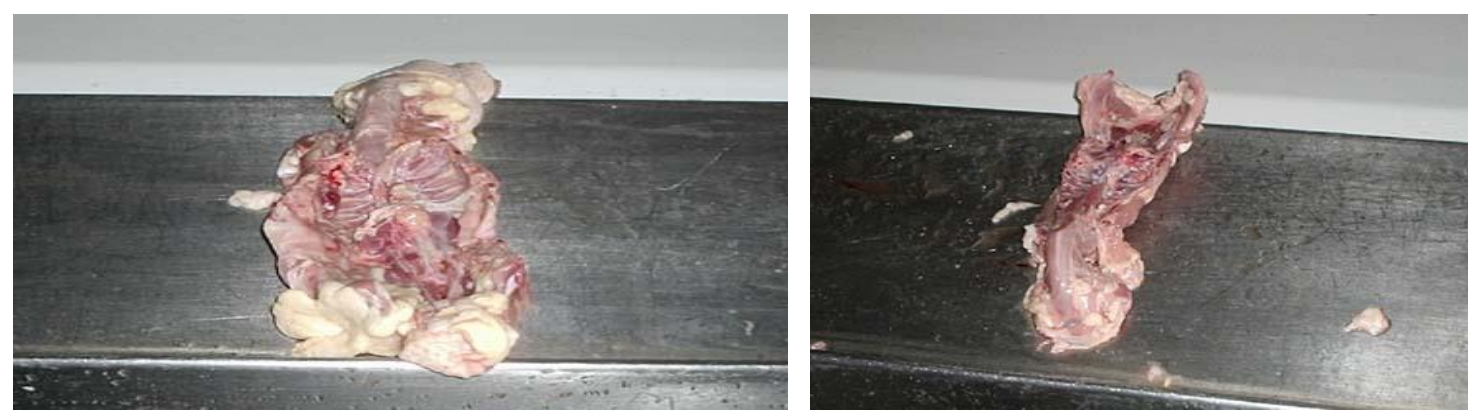

Figura 5: Comparação entre o corte do dorso inadequado (à esquerda) e o corte adequado à direita)

Através de entrevistas realizadas com colaboradores de diferentes níveis hierárquicos, acredita-se que este desperdício, um dos mais graves da empresa, poderia ser extinto ou minimizado por meio de uma política de treinamento, conscientização e motivação dos colaboradores, deixando claro a eles a importância do combate ao desperdício e como a diminuição desse aspecto negativo à empresa traz benefícios a si próprios. Porém, cabe também à empresa oferecer condições para a eficaz realização das atividades de trabalho, como tecnologia e tempo para a efetivação das tarefas de maneira adequada, ou seja, garantir recursos para a realização das atividades diárias com qualidade e produtividade satisfatória.

\section{CONCLUSÃO}

Na ótica do tema, constatamos a real necessidade de combater o desperdício, objetivando ganho de produtividade, a redução dos custos e a maximização dos lucros. Assim sendo, o mau aproveitamento dos insumos, bem como a incorreta utilização dos recursos técnicos, humanos e físicos levam a $\mathrm{X}$ à baixa competitividade no mercado. Por meio de uma política de melhor administração do capital humano disponível na empresa, bem como através da disponibilidade dos recursos necessários à efetividade da produção, acreditamos que o $\mathrm{X}$ reduzirá seus índices de desperdícios, sejam eles de qualquer modalidade. Dessa maneira, consideramos que o objetivo do momento é aproveitar de 
maneira eficiente as ferramentas disponíveis. Devido a má operacionalização das atividades do processo produtivo, os índices de produtividade não condizem com os de uma empresa que busca uma maior competitividade.

Observamos que a $\mathrm{X}$ tem como preocupação agregar valor ao seu portfólio de produtos, porém, não consegue motivar e, consequentemente, conscientizar seus colaboradores quanto à necessidade de minimizar os desperdícios e aumentar a produtividade, pois não é proporcionado aos colaboradores nenhum atrativo para tal finalidade.

Ao longo da pesquisa científica, concluímos que seja qual for o ramo de atuação da empresa, o combate ao desperdício deve ser parte integrante do planejamento estratégico, visando à perpetuidade.

Com isso, acreditamos que este trabalho é de grande valia e capaz de contribuir em futuras pesquisas sobre o assunto, que é de enorme interesse a sociedade visto a atual preocupação com a fome, podemos, por meio da pesquisa, evidenciar a grande quantidade de alimento não aproveitado e que poderia ser utilizado na alimentação dos próprios colaboradores.

\section{REFERÊNCIAS}

BULACH, M. Evitar desperdício é ato inteligente. O Estado de S. Paulo. São Paulo, 17 fev. 1998. Painel de Negócios.

CABAÑAS, L. A. Considerações sobre os sistemas de planejamento de materiais. 2003, 41 p. Apostila da disciplina de Administração de Recursos Materiais e Patrimoniais. Faculdade de Ciências Administrativas e Contábeis de Lins.

CABAÑAS, L. A. Considerações sobre a proposta do sistema MRP II. 2003, 45 p. Apostila da disciplina de Administração de recursos Materiais e Patrimoniais. Faculdade de Ciências Administrativas e Contábeis de Lins.

CHIAVENATO, I. Iniciação ao planejamento e controle de produção. São Paulo: Mcgraw-Hill, 1990, 117p. 
CORREA, H. L.; GIANESI, I. G. N. Just in Time, MRP II e OPT. 2. ed. São Paulo: Atlas, 1996, 186p.

COSTA, A. G., et al. Menos desperdício - Mais qualidade. 2003. Monografia (Graduação em Administração). Faculdades de Ciências Administrativas e Contábeis de Lins, Lins.

GIL, A. L. Qualidade total nas organizações. São Paulo: Atlas,1992. p. 110.

MACHLINE, C.; et al. Manual de administração da produção. 7. ed. Rio de Janeiro: FGV, 1984. 617 p.

MARTINS, P. G., LAUGENI, F. P. Adminisração da produção. São Paulo: Saraiva, 1998.

MOURA, R. A.; UMEDA, A. Sistema kanban de manufatura "just in time". 2. ed. São Paulo: Instituto de Movimentação e Armazenagem de Materiais, 1984. 273p.

QUINTANILHA, W.; ALGARTE, D. A História da qualidade e do programa brasileiro da qualidade e produtividade. Rio de Janeiro: INMETRO/SENAI, 2000. 143p.

ROCHA, D. Fundamentos técnicos da produção. São Paulo: Makron Books, 1995, 272p.

ROQUE, V. F. Processamento de carne de frango. 1996. Dissertação (Mestrado em Administração) - Universidade Federal de São Carlos, São Carlos. p. 1-17. Disponível em: <http://www.eps.ufsc.br/dissert96/vania>. Acesso em: 08 mar. 2004.

RUSSOMANO, V. H. Planejamento e controle da produção. 5. ed. São Paulo: Pioneira, 1995.

SILVA, A. C. Brasil, O País do Desperdício. 2001. Monografia (Pós-graduação em Administração) Faculdade de Ciências Administrativas e Contábeis de Lins, Lins.

SLACK, N.; et al. Administração da produção. São Paulo: Atlas, 1999. 